\title{
Evaluation of Diclofenac (DCF) Potassium as a Possible Predisposer of Benign Prostatic Hyperplasia in Wistar Albino Rats
} \author{
Ikechukwu Ubaoji ${ }^{2}$, and Ruqaiyatu Muhammad Adamu ${ }^{3}$

\footnotetext{
${ }^{1}$ Department of Biochemistry and Molecular Biology, Nasarawa State University, Keffi, Nasarawa State, Nigeria

${ }^{2}$ Department of Applied Biochemistry, Nnamdi Azikiwe University, Awka, Anambra State, Nigeria

${ }^{3}$ Department of Pharmacy, Federal Medical Centre, Keffi, Nasarawa State, Nigeria
}

Moses Zira Zaruwa ${ }^{1}$, Yusuf Bawa Muhammad ${ }^{1}$, Halima Sadiya Abdullahi ${ }^{1}$, Muhammed Abdullahi Ubana ${ }^{1 *}$, Kingsley

DOI: $10.36348 /$ sjbr.2020.v05i08.003

| Received: 05.07.2020 | Accepted: 19.07.2020 | Published: 22.08.2020

*Corresponding author: Ubana Muhammed Abdullahi

\section{Abstract}

Background: Diclofenac (DCF) is a drug widely consumed in developing countries like Nigeria, because of its fast and immediate effect on pains. Objectives: The high number of adult males falling victims to BPH made DCF a suspect in the predisposition to BPH. Methods: Thirsty Six (36) Male Wistar albino rats were divided into five groups of six animals each. Group 1; the Normal control (NC) was injected subcutaneously with olive oil only, Group 2; standard group treated with testosterone Propionate in olive oil ( $3 \mathrm{mg} / \mathrm{kg}$ b.wt.). Groups 3, 4, and 5 were treated with Diclofenac, potassium in solution as low ( $2 \mathrm{mg} / \mathrm{kg}$ b.wt.), mid (4 mg / kg b.wt.), and high (6 mg / kg b.wt.) doses respectively. All animals were fed same diets throughout the twelve (12) weeks. After this period, the rats were allowed to fast overnight then Blood samples were collected and analyzed for liver function, kidney function, lipid profile, prostate specific antigen (PSA), and haematological parameters. Results: The result showed an elevation in liver parameters; ALT, ALP, AST, total bilirubin, conjugated bilirubin in the treatment groups compared to the control. Conversely, the concentration of $\mathrm{Na}^{+}, \mathrm{Cl}^{-}$ and $\mathrm{HCO}_{3}{ }^{-}$revealed no significant difference compared to the control while urea and creatinine increased significantly. Haematological parameters showed increase in WBC, PCV, PLT in the treatments groups while RBC, Hb, MCV decreased. For lipid profile; Total cholesterol, TG, HDL and LDL increased significantly in the groups treated with mid and high dose DCF. Conclusion: The level of PSA was found to increase in all the treatment groups compared to the control. This result revealed that DCF-Potassium at high concentration can inter fare with the liver and kidney functions, lipid profile and haematological parameters as well as increasing PSA level. Thus, we conclude that persistent consumption of DCF can likely predispose to BPH.

Keywords: Benign prostate hyperplasia, Diclofenac, Haematological paramaters, Prostate specific antigen.

Copyright @ 2020: This is an open-access article distributed under the terms of the Creative Commons Attribution license which permits unrestricted use, distribution, and reproduction in any medium for non-commercial use (NonCommercial, or CC-BY-NC) provided the original author and source are credited.

\section{INTRODUCTION}

Benign Prostate Hyperplasia (BPH) is a progressive pathologic condition associated with elderly men and characterized by proliferation of prostatic tissues, prostate enlargement and consequent lower urinary tract symptoms [1]. These include urinary reluctance, frequent urination, weak stream, and nocturia [2]. Although nearly $70 \%$ of men, experience prostate enlargement, after the age of 50 , the pathogenesis of BPH is yet to be fully understood [2]. Within the transitional zone of the prostate, proliferation of both epithelial and stromal cells occurs. This accumulation of cells could lead to prostatitis and fibrosis, collectively causing lower urinary tract symptoms [3]. BPH development is associated with increased levels of dihydrotestosterone (DHT), produced from testosterone by the $5 \alpha$-reductase enzyme within the prostate glands [2,3].There is an increased accumulation of DHT in the prostate with aging which results in increased cell growth and hyperplasia [3].

Benign prostate hyperplasia also involves increased adrenergic tone in prostate smooth muscle mediated by $\alpha 1$-adrenoceptors [4]. Prostatic epithelial cells secrete Prostate-Specific Antigen (PSA); a glycoprotein in humans that performs various functions during copulation and fertilization $[4,5]$. Serum PSA levels are often elevated in prostate disorders such as $\mathrm{BPH}$ and are used as a clinical marker for disease prognosis $[5,6]$. 
The etiology of benign prostatic hyperplasia is complex and not completely elucidated but involves age-related hormonal alterations, metabolic syndrome and inflammation [6]. Also, several studies have shown that other processes such as chronic inflammation and increased oxidative stress may play important roles in the development of BPH [6].

Inflammatory disorders may include; musculoskeletal complaints, especially arthritis, rheumatoid arthritis, dental pain among others [7]. Diclofenac is used commonly to treat mild to moderate postoperative or post-traumatic pain, in particular when inflammation is also present, and is effective against menstrual pain and endometriosis [7, 8]. Researches have shown that, there are different risk factors which could predispose to $\mathrm{BPH}$; such as drugs, age, consumption of alcohol and dietary pattern, but amongst these, painkiller drugs are the most common drugs often consume at later age due to arthritis and other ailments [8]. In this research, we studied the effect of DCF-Potassium, as a predisposer of Benign Prostate Hyperplasia (BPH) in rat model.

\section{MATERIALS AND METHODS Materials and Reagents}

Diclofenac Potassium 50mg, Testosterone propionate injection, Olive oil, Diethyl ether Pnitrophenylphosphate, buffer solution for ALP containing $0.5 \mathrm{mmol}$ magnesium chloride, 2,4dinitrophenylhydrazine, Buffer solution containing $100 \mathrm{mmol} / \mathrm{L}$ phosphate buffer, Monoclonal anti-free PSA alkaline phosphate, Standard Cholesterol reagents, Standard triglycerides, Phosphotungstate, Magnesium chloride.

\section{Experimental Design and Animal Treatment}

Thirsty Six (36) Male Wistar albino rats (24) weeks were purchased from National Veterinary Research Institute (NVRI), Vom. Plateau State, Nigeria. They were kept in the Animal House of the Department of Biochemistry and Molecular Biology, Nasarawa State University, Keffi; with proper ventilation condition and 12 hours day light as well as 12 hours dark night cycle. The rats were weighed and divided into five groups of six animals each and acclimatized for two weeks before the experiment commenced. Group 1; the Normal control (NC) was injected subcutaneously with the vehicle (olive oil) only and served diet. Group 2; standard group treated with testosterone Propionate in olive oil (3 mg / kg b.wt.). Groups 3, 4, and 5 were treated with Diclofenac, potassium in solution as low (2 $\mathrm{mg} / \mathrm{kg}$ b.wt.), mid (4 mg / kg b.wt.), and high (6 mg / kg b.wt.) doses respectively, and served feed. The experiment lasted for twelve (12) weeks [9].

\section{Animal Sacrifice and Blood Sample Collection}

After the treatment period, the rats was allowed to fast overnight and sacrificed under mild euthanasia with pentobarbital. Blood samples were collected by cardiac perforation into plain, and EDTA bottles, respectively for chemistry and hematological assays. The blood in the plain bottles was allowed to clot and the serum separated at $3500 \mathrm{rpm}$ for $15 \mathrm{~min}$ was used for determination of Prostate Specific Antigen (PSA), Kidneys and liver functions.

\section{Determination of Serum Prostate specific antigen (PSA)}

The serum Prostate Specific Antigen (PSA) levels were determined with a PSA ELISA kit according to the manufacturer's instructions (Rapid Labs. Ltd, Colchester, Essex, UK) The absorbance was measured at $450 \mathrm{~nm}$ using a micro plate reader (BioRad Laboratories, Inc.). The values were expressed as ng protein $\mathrm{mLG}$.

\section{Biochemical Analysis}

Biochemical analysis were carried out to determine liver function (serum concentrations of AST, ALT, ALP, conjugated and total bilirubin), Kidney function (Urea, Creatinine and electrolytes) using Automated Biochemical Analyzer. While kits (Bio-Rad Company), were used to assay for lipid profile (Total cholesterol, VLDL, LDL and HDL) according to manufacturer's instructions.

\section{STATISTICAL ANALYSIS}

One-way analysis of variance was used in analyzing the results using the Predictive Analytics Software (International Business Machines (IBM), United States) Statistics 18 package. All the results were expressed as mean \pm standard error and $P<0.05$ was taken to be significant [10].

Table-1: Effect of Diclofenac on Liver Function of Rats

\begin{tabular}{|l|l|l|l|l|l|}
\hline Groups & $\begin{array}{l}\text { Total Bil. } \\
(\boldsymbol{\mu m o l} / \mathbf{L})\end{array}$ & $\begin{array}{l}\text { Conjugated Bil. } \\
(\boldsymbol{\mu} \mathrm{mol} / \mathbf{L})\end{array}$ & $\begin{array}{l}\text { ALP } \\
(\mathbf{I U} / \mathbf{L})\end{array}$ & $\begin{array}{l}\text { ALT } \\
(\mathbf{I U} / \mathbf{L})\end{array}$ & $\begin{array}{l}\text { AST } \\
(\mathbf{I U} / \mathbf{L})\end{array}$ \\
\hline 1 & $3.30 \pm 0.08^{\mathrm{a}}$ & $0.35 \pm 0.10^{\mathrm{c}}$ & $197.10 \pm 13.02^{\mathrm{g}}$ & $80.00 \pm 0.28^{\mathrm{i}}$ & $53.00 \pm 0.43^{\mathrm{m}}$ \\
\hline 2 & $3.30 \pm 0.04^{\mathrm{a}}$ & $1.35 \pm 0.02^{\mathrm{d}}$ & $196.00 \pm 21.43^{\mathrm{g}}$ & $210.00 \pm 25.2^{\mathrm{j}}$ & $210.00 \pm 25.12^{\mathrm{o}}$ \\
\hline 3 & $3.30 \pm 0.04^{\mathrm{a}}$ & $3.65 \pm 0.36^{\mathrm{e}}$ & $276.85 \pm 4.53^{\mathrm{h}}$ & $75.15 \pm 4.93^{\mathrm{i}}$ & $129.60 \pm 26.45^{\mathrm{n}}$ \\
\hline 4 & $5.60 \pm 0.00^{\mathrm{a}}$ & $2.80 \pm 1.2^{\mathrm{f}}$ & $239.80 \pm 28.00^{\mathrm{h}}$ & $97.50 \pm 0.24^{\mathrm{k}}$ & $160.23 \pm 23.06^{\mathrm{p}}$ \\
\hline 5 & $6.25 \pm 3.22^{\mathrm{b}}$ & $3.45 \pm 0.53^{\mathrm{e}}$ & $193.65 \pm 4.12^{\mathrm{g}}$ & $94.42 \pm 36.47^{\mathrm{l}}$ & $48.95 \pm 1.75^{\mathrm{m}}$ \\
\hline
\end{tabular}

Results are expressed in Means \pm SD $(n=6)$ Mean values with different letters as superscripts down the rows are considered significant at $\mathrm{p}<0.05$. Group $1=$ Negative Control (treated with vehicle), Group $2=$ Testosterone treated, Group $3=$ Low dose + normal feed, Group $4=$ Middle dose + normal feed, Group $5=$ High dose + normal feed 
As shown in table, total bilirubin concentration increased significantly $(\mathrm{P}<0.05)$ in groups 4 when compared to the control group while conjugated bilirubin increased significantly $(\mathrm{P}<0.05)$ in all the treatment groups compared to group 1. ALP levels significantly $(\mathrm{P}<0.05)$ increased in groups 3,4 and 5 compared to the control. ALT levels was found to be significantly $(\mathrm{P}<0.05)$ high in groups $2,4,5$ and significantly $(\mathrm{P}<0.05)$ lower in groups 3 when compared to the control group while AST levels increased significantly $(\mathrm{P}<0.05)$ in groups 2,3 , and 4 respectively.

Table-2: Effect of Diclofenac on Kidney Function of Rats

\begin{tabular}{|l|l|l|l|l|l|l|}
\hline Groups & $\begin{array}{l}\mathbf{N a}^{+} \\
(\mathbf{m m o l} / \mathbf{L})\end{array}$ & $\begin{array}{l}\mathbf{K}^{+} \\
(\mathbf{m m o l} / \mathbf{L})\end{array}$ & $\begin{array}{l}\mathbf{C l}^{-} \\
(\mathbf{m m o l} / \mathbf{L})\end{array}$ & $\begin{array}{l}\mathbf{H C O}_{3}^{-} \\
(\mathbf{m m o l} / \mathbf{L})\end{array}$ & $\begin{array}{l}\text { Urea } \\
(\mathbf{m m o l} / \mathbf{L})\end{array}$ & $\begin{array}{l}\text { Creatinine } \\
(\mathbf{m m o l} / \mathbf{L})\end{array}$ \\
\hline 1 & $151.42 \pm 0.16^{\mathrm{a}}$ & $3.00 \pm 0.04^{\mathrm{c}}$ & $103.87 \pm 0.18^{\mathrm{g}}$ & $19.77 \pm 0.14^{\mathrm{k}}$ & $5.67 \pm 0.06^{\mathrm{n}}$ & $76.10 \pm 0.04^{\mathrm{r}}$ \\
\hline 2 & $149.00 \pm-0.53^{\mathrm{a}}$ & $3.20 \pm 0.16^{\mathrm{c}}$ & $100.87 \pm 0.14^{\mathrm{g}}$ & $21.10 \pm 0.81^{\mathrm{k}}$ & $6.62 \pm 0.57^{\mathrm{n}}$ & $68.92 \pm 1.86^{\mathrm{r}}$ \\
\hline 3 & $148.05 \pm 1.02^{\mathrm{a}}$ & $3.93 \pm 0.28^{\mathrm{c}}$ & $102.25 \pm 0.28^{\mathrm{g}}$ & $18.15 \pm 0.77^{1}$ & $6.35 \pm 0.36^{\mathrm{n}}$ & $72.55 \pm .44^{\mathrm{r}}$ \\
\hline 4 & $150.70 \pm 0.73^{\mathrm{a}}$ & $5.50 \pm 1.87^{\mathrm{d}}$ & $102.00 \pm 0.48^{\mathrm{g}}$ & $19.45 \pm 0.36^{\mathrm{k}}$ & $12.55 \pm 3.02^{\mathrm{o}}$ & $95.10 \pm 9.55^{\mathrm{s}}$ \\
\hline 5 & $152.45 \pm 0.12^{\mathrm{a}}$ & $5.43 \pm 1.10^{\mathrm{d}}$ & $94.95 \pm 1.10^{\mathrm{h}}$ & $17.10 \pm 0.00^{1}$ & $9.10 \pm 0.40^{\mathrm{q}}$ & $108.00 \pm 1.22^{\mathrm{t}}$ \\
\hline
\end{tabular}

Results are expressed in Means \pm SD $(6=4)$. Mean values with different letters as superscripts down the rows are considered significant at $\mathrm{p}<0.05$, Group $1=$ Negative Control (untreated), Group $2=$ testosterone treated, Group $3=$ Low dose + normal feed, Group $4=$ mid dose + normal feed, Group $5=$ High dose + normal feed.

In table 2 above, the concentration of Sodium and chloride ions in the treatment groups showed no significant difference $(\mathrm{P}<0.05)$ compared to control while Potassium ion concentration slightly increased in the treatment groups. Bicarbonate ion decreased significantly $(\mathrm{P}<0.05)$ in groups 3 and 5 and increased significantly $\quad(\mathrm{P}<0.05)$. Urea and creatinine concentration increased significantly $(\mathrm{p}<0.05)$ in groups 4 and 5 compared to the control.

Table-3: Effect of Diclofenac on Lipid Profile of Rats

\begin{tabular}{|l|l|l|l|l|}
\hline Groups & $\begin{array}{l}\text { Total Chol. } \\
(\mathbf{m m o l} / \mathbf{L})\end{array}$ & $\begin{array}{c}\text { HDL } \\
(\mathbf{m m o l} / \mathbf{L})\end{array}$ & $\begin{array}{l}\text { TG } \\
(\mathbf{m m o l} / \mathbf{L})\end{array}$ & $\begin{array}{l}\mathbf{L D L} \\
(\mathbf{m m o l} / \mathbf{L})\end{array}$ \\
\hline 1 & $1.10 \pm 0.00^{\mathrm{a}}$ & $0.50 \pm 0.04^{\mathrm{e}}$ & $0.90 \pm 0.04^{\mathrm{i}}$ & $0.40 \pm 0.04^{\mathrm{m}}$ \\
\hline 2 & $1.30 \pm 0.00^{\mathrm{a}}$ & $0.48 \pm 0.06^{\mathrm{e}}$ & $0.70 \pm 0.08^{\mathrm{l}}$ & $0.50 \pm 0.00^{\mathrm{m}}$ \\
\hline 3 & $1.80 \pm 0.08^{\mathrm{b}}$ & $0.70 \pm .40^{\mathrm{f}}$ & $0.70 \pm 0.00^{\mathrm{l}}$ & $0.65 \pm 0.36^{\mathrm{m}}$ \\
\hline 4 & $2.20 \pm 0.32^{\mathrm{c}}$ & $0.80 \pm 0.32^{\mathrm{g}}$ & $1.05 \pm 0.12^{\mathrm{k}}$ & $3.55 \pm 0.44^{\mathrm{n}}$ \\
\hline 5 & $2.10 \pm 0.00^{\mathrm{d}}$ & $1.30 \pm 0.24^{\mathrm{h}}$ & $0.65 \pm 0.04^{\mathrm{l}}$ & $1.35 \pm 0.85^{\mathrm{o}}$ \\
\hline
\end{tabular}

Results are expressed in Means \pm SD $(6=4)$. Mean values with different letters as superscripts down the rows are considered significant at $\mathrm{p}<0.05$, Group $1=$ Negative Control (untreated), Group $2=$ testosterone treated, Group $3=$ Low dose + normal feed, Group $4=$ mid dose + normal feed, Group $5=$ High dose + normal feed.

In table 3 above, Total cholesterol concentration was observed to increase significantly $(\mathrm{p}$ $<0.05)$ in groups 4 and 5 compared to the control. HDL concentration increased significantly $(\mathrm{P}<0.05)$ in groups 3, 4 and 5 compared to the control. Triglycerides concentration increased significantly $(\mathrm{P}<0.05)$ in group 4 compared to the control. LDL concentration increased significantly $(\mathrm{P}<0.05)$ in the treatment groups compared to the control except in groups 2 and 3 .

Table-4: Effect of Diclofenac on PSA Levels of Rats

\begin{tabular}{|c|c|}
\hline Group & PSA (ng/ml) \\
\hline Group 1 & $0.10 \pm 0.00^{\mathrm{a}}$ \\
\hline Group 2 & $0.48 \pm 0.17^{\mathrm{c}}$ \\
\hline Group 3 & $2.10 \pm 0.40^{\mathrm{b}}$ \\
\hline Group 4 & $0.99 \pm 0.05^{\mathrm{c}}$ \\
\hline Group 5 & $0.95 \pm 0.25^{\mathrm{c}}$ \\
\hline
\end{tabular}

Results are expressed in Means \pm SD $(6=4)$. Mean values with different letters as superscripts down the rows are considered significant at $\mathrm{p}<0.05$, Group $1=$ Negative Control (untreated), Group $2=$ testosterone treated, Group $3=$ Low dose + normal feed, Group $4=$ mid dose + normal feed, Group $5=$ High dose + normal feed. 
Table-5: Effect of Diclofenac on hematological parameters in BPH rat models

\begin{tabular}{|c|c|c|c|c|c|c|}
\hline Groups & $\begin{array}{l}\text { WBC } \\
\left(10^{9 / 1} \mathrm{~g} / \mathbf{l}\right)\end{array}$ & $\begin{array}{l}\text { RBC } \\
\left(10^{12 / 1} \mathrm{~g} / \mathrm{l}\right)\end{array}$ & $\begin{array}{l}\mathrm{Hb} \\
(\mathrm{g} / \mathrm{dl})\end{array}$ & $\begin{array}{l}\text { PCV } \\
(\%)\end{array}$ & $\begin{array}{l}\text { MCV } \\
\text { (FL) }\end{array}$ & $\begin{array}{l}\text { PLT } \\
\left(10^{9 / 1} \mathbf{g} / \mathbf{l}\right)\end{array}$ \\
\hline 1 & $6.30 \pm 0.89^{b}$ & $6.00 \pm 0.04^{\mathrm{c}}$ & $23.87 \pm 0.75^{\mathrm{h}}$ & $19.77 \pm 0.41^{\mathrm{m}}$ & $76.10 \pm 2.03^{t}$ & $253.33 \pm 2.03^{\mathrm{w}}$ \\
\hline 2 & $149.00 \pm 0.10^{\mathrm{a}}$ & $6.20 \pm 0.08^{\mathrm{c}}$ & $20.87 \pm 0.21^{\mathrm{h}}$ & $21.10 \pm 0.61^{\mathrm{m}}$ & $68.92 \pm 0.61^{t}$ & $199.50 \pm 0.61^{x}$ \\
\hline 3 & $6.300 \pm 44.90^{\mathrm{b}}$ & $2.65 \pm 0.53^{f}$ & $8.80 \pm 1.38^{i}$ & $33.65 \pm 1.51^{\mathrm{s}}$ & $100.95 \pm 3.30^{\mathrm{u}}$ & $112.25 \pm 0.50^{y}$ \\
\hline 4 & $6.40 \pm 0.29^{b}$ & $3.90 \pm 0.24^{\mathrm{e}}$ & $12.90 \pm 0.40^{j}$ & $33.15 \pm 1.02^{\mathrm{s}}$ & $98.95 \pm 3.06^{\mathrm{u}}$ & $202.00 \pm 4.89^{z}$ \\
\hline 5 & $7.20 \pm 0.00^{\mathrm{b}}$ & $4.55 \pm 0.04^{\mathrm{d}}$ & $15.25 \pm 0.12^{\mathrm{k}}$ & $33.50 \pm .57^{\mathrm{s}}$ & $100.00 \pm 1.79^{u}$ & $319.50 \pm 13.47^{\beta}$ \\
\hline
\end{tabular}

Results are expressed in Means \pm SD $(6=4)$. Mean values with different letters as superscripts down the rows are considered significant at $\mathrm{p}<0.05$, Group $1=$ Negative Control (untreated), Group $2=$ testosterone treated, Group $3=$ Low dose + normal feed, Group $4=$ mid dose + normal feed, Group $5=$ High dose + normal feed.

The amount of PSA increased significantly (P $<0.05)$ in the treatment groups when compared to the control group except group 2. RBC and $\mathrm{Hb}$ levels in groups 2, 4, 5 decreased significantly $(\mathrm{P}<0.05)$ while WBC increased in group2, MCV level increased significantly in the treatment groups while platelet decreased in all the groups except in group5 where it increased.

\section{DISCUSSION}

The biochemical effect of the drug diclofenac (DCF) Potassium a nonsteroidal anti-inflammatory drug (NSAID) was studied concurrently with BPH induced rat models. In this study, DCF Potassium showed alterations in haematological parameters, lipid profile, liver and kidney functions as well as prostate specific antigen (PSA). Similar alterations have been previously observed in human beings and dogs as also observed in WBC of rat across the groups with significant $(\mathrm{P}<0.05)$ elevation in group $2 \& 3$. An increased in WBC counts can occur aberrantly as a result of an infection, cancer, or prescence of xenobiotics [10]. The decrease in RBC, $\mathrm{Hb}$ and increase in WBC by DCF-Potassium was previously reported [11]. The decrease in blood parameters caused by this drug may be attributed to its harmful effects on bone marrow and haematopoietic organs [12, 13]. The Hb, PCV and MCV levels all showed varying alterations (Table 5). The platelets levels was lowest at low concentration of DCF but became highest at high dose. This indicates that although DCF is an anti-inflammatory drug at low dose at high concentration it has negative effect at very high concentration by inducing inflammatory process [13, 14]. This is evident from the elevated levels of the WBC \& PLT in all the dichlofenac treatment groups. The results of the lipid profile of the rats showed significant alterations in the serum total cholesterol across the treated groups (Table 3). The increase in total cholesterol level in the testosterone group (BPH model) compared to the control and the treatment groups (35 ) is a clear pointer that, mimicking the life styles of individuals in regards to linking it to BPH may be very correct $[14,15]$. The increase in cholesterol level could probably be triggered as a result of DCF-Potassium effect on the liver; leading to hepato-biliary impairment as evident by the substantial increase in serum liver enzymes. This phenomenon would have prevented the transport of triglycerides from the hepatocytes, thus rendering lower amounts of triglycerides, in the serum [15]. Based on the fact that, the liver is the vital tissue of lipid metabolism, drug-induced liver impairment raised total cholesterol levels, while HDL-cholesterol levels decreased alongside those of triglycerides and LDL-cholesterol, respectively $[16,12]$. This implies that DCF-Potassium interaction with dietary xenobiotics could lead to the generation of ROS and RNS [15] which undoubtedly enhances oxidative stress in several pathophysiological conditions which may include the prostate gland leading to $\mathrm{BPH}$.

A previous report on diclofenac induced rats showed kidney and liver function aberrations [17, 18]. Diclofenac effect on renal function showed that, it impaired urinary output within 10 minutes of its administration by injection in humans [12]. It was observed that, this effect was as a result of the inhibition of prostaglandin (PG) synthesis in animals and $P G$ is a part of prostatic secretion [12]. It is no doubt therefore that DCF negatively affects the prostate gland. It is equally known that PGs are synthesized at sites of tissue damage or infection, where it causes inflammation and pain. The prostate gland by its nature as soft tissue is vulnerable and therefore links up with the prediction that DCF-Potassium is most likely toxic to the gland. A study had suggested earlier that Diclofenac causes muscle contraction in the uterus and that higher concentration were linked to menstrual cramps caused by endometriosis [17]. This claim supports our deduction of the negative effect of diclofenac on the soft tissues like the prostate gland. The biochemical markers evaluated in the rats for DCFPotassium effect on liver function, showed alterations in total bilirubin, conjugate bilirubin, ALP, AST and ALT [18]. The other groups (3-5) however, were significantly higher. This would have been triggered by the interaction between DCF and dietary xenobiotics. It justified the claim of hepatotoxicity in rats by DCF in a dose dependent pattern $[18,12]$. The biomarkers in the kidney studies showed significant alterations in urea and creatinine levels, as well as $\mathrm{K}^{+}$. Urea and creatinine are excreted solely through the kidney; however, damage to the kidney will make it inefficient to excrete both urea and creatinine, resulting in their accumulation in the blood. The kidneys role in the elimination of toxic xenobiotics, cannot be underscored, hence its exposure to toxic materials compared to other organs 
beside liver. Our study is consistent with earlier reports that showed increased levels of serum creatinine and urea in mice exposed to diclofenac and these are indications of acute kidney injury (AKI) [12]. It is obvious that AKI increases the free radical levels within the system, which tends to cause inflammation of various organs and especially very soft tissues such as the prostate gland being most vulnerable [19]. The prostate specific antigen (PSA), values showed significant $(\mathrm{P}<0.05)$ alteration as well, which suggest injury to tissues. The PSA is produced by all cells in normal as well as malignant cells of the prostate gland [20]. It is known that, the PSA levels in men vary over time according to age and physiological conditions [20]. Certain conditions are known to cause alterations in PSA levels in men, such as prostatitis or urinary tract infection $[20,1]$. The effect of testosterone propionate injection in laboratory animals has contradictory effect, but most recent report showed correlation between levels of PSA after testosterone injection [1]. The current study also showed a slight raise in PSA level. The levels of PSA across the groups were significantly $(\mathrm{P}<0.05)$ increased, compared to the control and testosterone groups, respectively. DCF have been shown to be hepato-toxic and nephro-toxic from this research predictively as a result of increased generation of free radicals which in turn exacerbated inflammatory response and other cellular processes, which initiated the promotion and progression of abnormal cell proliferation, enlargement and possible neoplasms leading to cancer [8]. The significant increase in levels of PSA in all the treatment groups is indictment of DCF as a predisposer of BPE and possibly BPH.

\section{CONCLUSION}

From the results obtained in this research, we concluded that DCF is hepatotoxic, nephrotoxic, thus predisposes tissue damage, inflammation and oxidative stress which collectively could lead to elevated PSA a prime marker of BPE. Further study, on the effect of different doses of DCF on antioxidant enzymes are recommended.

\section{Conflict of interest}

The authors declared no conflict of interest

\section{ACKNOWLEDGEMENT}

The authors are indebted to the Department of Biochemistry and Molecular Biology, Faculty of Natural and Applied Sciences, Nasarawa State University, Keffi, Nigeria.

\section{REFERENCES}

1. Song, J.-H., Hwang, B., Chung, H. J., Moon, B., Kim, J.-W., Ko, K., Kim, B.-W., Kim, W.-R., Kim, W.-J., Myung, S. C., \& Moon, S.-K. (2020). Peanut Sprout Extracts Cultivated with Fermented Sawdust Medium Inhibits Benign Prostatic Hyperplasia In Vitro and In Vivo. World J Mens Health, 38.
2. Nemr, E., El Helou, E., Mjaess, G., Semaan, A., \& Chebel, J. A. (2020). Prospective Multicenter Open-Label One-Arm Trial Investigating a Pumpkin Seed, Isoflavonoids, and Cranberry Mix in Lower Urinary Tract Symptoms/Benign Prostatic Hyperplasia: A Pilot Study. Advances in Urology, 2020, 6325490.

3. McCormick, B. J., \& Raynor, M. C. (2020). The Prostate and Benign Prostatic Hyperplasia Prostatic Artery Embolization (pp. 1-9): Springer.

4. Foo, K. T. (2019). What is a disease? What is the disease clinical benign prostatic hyperplasia (BPH)? World journal of urology, 37(7), 1293-1296.

5. Rao, A., \& Grant, R. (2020). The effect of Trigonella foenum- graecum extract on prostatespecific antigen, and prostate function in otherwise healthy men with benign prostate hyperplasia. Phytotherapy Research, 34(3), 634-639.

6. Santos, H. O., Howell, S., \& Teixeira, F. J. (2019). Beyond tribulus (Tribulus terrestris L.): The effects of phytotherapics on testosterone, sperm and prostate parameters. Journal of Ethnopharmacology.

7. Al-Lawati, H., Vakili, M. R., Lavasanifar, A., Ahmed, S., \& Jamali, F. (2020). Reduced Heart Exposure of Diclofenac by Its Polymeric Micellar Formulation Normalizes CYP-Mediated Metabolism of Arachidonic Acid Imbalance in An Adjuvant Arthritis Rat Model: Implications in Reduced Cardiovascular Side Effects of Diclofenac by Nanodrug Delivery. Molecular Pharmaceutics.

8. Miklos, I., \& Ioiart, I. (2019). The Influence of Risk Factors on Epigenetic Changes in Patients with Benign Prostate Hypertrophy. Romanian Journal of Urology, 18(1), 12-16.

9. Navyasree, S., \& Babu, A. K. (2019). Benign Prostatic Hyperplasia: A Noncancerous Increase in Size of Prosate Gland. Journal of the Gujarat Research Society, 21(9), 325-333.

10. Elsharkawy, E. E., Yahia, D., \& El-Nisr, N. A. (2013). Sub-chronic exposure to chlorpyrifos induces hematological, metabolic disorders and oxidative stress in rat: Attenuation by glutathione. Environmental toxicology and pharmacology, 35(2), 218-227.

11. Vargas-Sánchez, K., Garay-Jaramillo, E., andGonzález-Reyes, R. E. (2019). Effects of Moringa oleifera on Glycaemia and Insulin Levels: A Review of Animal and Human Studies. Nutrients, 11(12), 2907.

12. Aycan, İ. Ö., Elpek, Ö., Akkaya, B., Kıraç, E., Tuzcu, H., Kaya, S., Coşkunfırat, N., \& Aslan, M. (2018). Diclofenac induced gastrointestinal and renal toxicity is alleviated by thymoquinone treatment. Food and Chemical Toxicology, 118, 795-804.

13. Uraki, M., Kawase, A., Sayama, H., Matsushima, Y., \& Iwaki, M. (2017). Effects of adjuvantinduced inflammation on disposition of Diclofenac 
and its metabolites in perfused rat liver. Journal of pharmaceutical sciences, 106(4), 1175-1182.

14. Smith, D. P., Weber, M. F., Soga, K., Korda, R. J., Tikellis, G., Patel, M. I., Clements, M. S., Dwyer, T., Latz, I. K., andBanks, E. (2014). Relationship between lifestyle and health factors and severe lower urinary tract symptoms (LUTS) in 106,435 middle-aged and older Australian men: populationbased study. PloS one, 9(10), e109278-e109278.

15. Motawi, T. K., Ahmed, S. A., El-Boghdady, N. A., Metwally, N. S., \& Nasr, N. N. (2020). Impact of betanin against paracetamol and diclofenac induced hepato-renal damage in rats. Biomarkers, 25(1), 86-93.

16. Curcelli, E. C., Muller, S. S., \& Novelli Filho, J. L. V. B. (2008). Beneficial effects of diclofenac therapy on serum lipids, oxidized low-density lipoprotein and antioxidant defenses in rats. Life Sciences, 82(15), 892-898.

17. Perez Vallina, J. R., Menendez Antolin, L., Cantabrana, B., Sanchez, M., \& Hidalgo, A. (1995). Involvement of sodium/calcium exchange in the diclofenac-induced spasmolytic effect on rat uterus. General pharmacology, 26(6), 1249-1253.

18. Sánchez, S., De La Lastra, C. A., Ortiz, P., Motilva, V., \& Martín, M. J. (2002). Gastrointestinal Tolerability of Metamizol, Acetaminophen, and Diclofenac in Subchronic Treatment in Rats. Digestive Diseases and Sciences, 47(12), 27912798.

19. Zeng, M., Qi, M., Wang, Y., Xu, R., Wu, Y., Li, M., Zheng, X., \& Feng, W. (2020). 5-Omethyldihydroquercetin and cilicicone $\mathrm{B}$ isolated from Spina Gleditsiae ameliorate lipopolysaccharide- induced acute kidney injury in mice by inhibiting inflammation and oxidative stress via the TLR4/MyD88/TRIF/NLRP3 signaling pathway. International Immunopharmacology, 80, 106194.

20. Yamazaki, M., Yoshida, K., Terayama, N., Kobayashi, K., Hayashi, N., Hayashi, S., \& Gabata, T. (2020). CT and MRI findings of a stromal tumour of uncertain malignant potential of the prostate. European Journal of Radiology Open, 7, 100233. 